\title{
COMPARISON OF PERCUTANEOUS PEDICLE SCREW FIXATION AND PEDICAL SCREW FIXATION IN CONVENTIONAL INCISION IN THORACOLUMBAR FRACTURE
}

\author{
Surojn Jeamanukulkit
}

Department of Orthopaedics, Rayong Hospital, Rayong, Thailand

\begin{abstract}
Background: Originally, patients with unstable thoracolumbar spine fracture were treated using pedicle screw fixation, a conventional incision. However, the small incision percutaneous pedicle screw fixation (PPSF), a new device, has been recently introduced which could save surgery time, reduce blood loss and improve clinical recovery.

Objective: This study aimed to evaluate postoperative outcomes of the PPSF, compared with the open pedicle screw fixation (OPSF) in conventional incision among patients with thoracolumbar fracture.

Methods: A retrospective study of 54 cases of patients with thoracolumbar spine fracture without neurological deficit was included in the study. The data were collected from medical records of patients admitted to Rayong Hospital from January 2017-December 2019.

Results: Patients aged from 18-46 years (32.35 18.52$)$ were mostly males $(59.2 \%)$. Types of fracture included burst (72.22\%). The most common level of thoracolumbar spine fracture was L1 (37.04\%). Mostly, the cause of injury was fall from height (53.70\%). The mean postoperative stays in the PPSF and OPSF groups were significant, $3.09 \pm .59$ and $6.16 \pm 1.003$ days, respectively $(p<0.05)$. The mean intraoperative blood losses of the PPSF and OPSF groups significantly differed, $44.35 \pm 15.02$ and $466.13 \pm 87.92 \mathrm{~mL}$, respectively $(p<0.01)$. However, the mean kyphotic angle reduction of the PPSF $(24.43 \pm 2.74$ degrees $)$ and OPSF (24.87 \pm 2.55 degrees) groups did not significantly differ $(p>0.1)$. The mean postoperative pain score (VAS) at the first day in the PPSF and OPSF groups were 6.43 \pm .94 and $6.61 \pm .98$, respectively, which did not significantly differ $(p>0.1)$.

Conclusion: PPSF spinal fracture treatment could reduce the amount of bleeding during surgery and reduce the length of hospital stay. However, the results of both types of surgery did not differ regarding postoperative pain, decreased kyphotic angle and surgical time.
\end{abstract}

Keywords: Thoracolumbar Fracture, Percutaneous pedicle screw fixation, Open pedicle screw fixation

J Southeast Asian Med Res 2021: 5 (2):78-83

https://www.jseamed.org

Correspondence to:

Jeamanukulkit S, Department of Orthopaedics, Rayong Hospital, Rayong, Thailand

E-mail: surojn.ryh@gmail.com

Received: 4 July 2021

Revised: 18 August 2021

Accepted: 31 August 2021 


\section{Introduction}

Spine fracture has been found especially at the thoracolumbar junction level (T10-L2) where biomechanical transferred area and considerable motion are involved. ${ }^{(1,2)}$ The incidence of this injury in North America was 160,000 persons per year which caused abnormal spine structure (kyphotic deformity) with neurological injury.

The classification of injury at this area used the three-column concept as described by Denis $\mathrm{F}^{(3)}$ This concept divided patients in four groups under biomechanical theory, namely, compression fracture, burst fracture, flexion-distraction injury and fracture dislocation. In 2005, Vaccaro et al. ${ }^{(4)}$ proposed the thoracolumbar injury and severity score (TLICs) considering three aspects, i.e., biomechanical spine fracture combined with the context of Denis's theory, injury at the posterior ligamentous complex and neurological spinal injury. All of these aspects have been applied and used as guidelines for patterns and treatment methods.

The unstable fracture or TLICs $\geq 4$ with neural injury was treated using the open conventional incision. Pedicle screws were applied to fix at the spinal body and reduction \& decompression followed the standard treatment. ${ }^{(5,6)}$

On the other hand, the unstable spine fracture without neurological injury could be treated using percutaneous pedicle screw fixation which saved time during surgery. In addition, this approach reduced blood loss, decreased dissection tissue and improved clinical recovery faster than the old method. ${ }^{(7,8)}$

The important instrument assisting percutaneous pedicle screw fixation was a guide wire and a cannulated screw to apply insertion at the pedicle only. Fluoroscope assisted evaluating the proper site and direction of screw during surgery. Open surgery splinted the muscles between the multi fidus and longissimus (Wiltse's approach). ${ }^{(14-16)}$ This retrospective study considered the appropriateness, safety and efficacy of both techniques.

\section{Methods}

The retrospective study was conducted at Rayong Hospital and approved by the Ethics Committee of Rayong Hospital (RYH REC No.
E030/2563). The inclusion criteria included thoracolumbar and unstable fractures. The exclusion criteria included TLICs $<4$ scores, neurological deficit, and multiple organ injuries. From January 2017 to December 2019, 54 thoracolumbar fractures operated at Rayong Hospital were enrolled in the study. The data were searched from the patients' medical records, i.e., age, sex, levels of spinal fracture, and causes and outcomes of treatment. The participants presenting TL spine fracture were measured using kyphotic or Cobb angle and identified configuration of fracture from a plain film (TL spine AP-lateral).

The patients were divided in two groups. The percutaneous pedicle screw fixation or the PPSF group constituted the study group while the open splint muscle long segment pedicle screw fixation or the OPSF group constituted the control group. Neither group showed decompression or posterior spinal fusion, and both used an indirect reduction technique in the prone position. A distraction device was applied in the field of surgery and controlled precise operation using fluoroscopy.

The incision using the PPSF technique was nearly out bounder of pedicle $15 \mathrm{~mm}$ in length and was checked with fluoroscope in the AP view. The next step was splitting the paraspinal muscle using a small incision to check position of the facet joint. Then a cannulated awl was applied at the outer cortex to insert a guide wire. The guide wire was passed through inside the bone and rechecked with fluoroscopy in the AP and lateral views. When it stayed in a precise position, cannulated tap was applied to make the entry point at the pedicle. The pedicle screw was inserted after removing the guide wire and its position was checked using fluoroscopy. When all pedicle screws were inserted, the proper lengths rod of both sides were replaced. After rechecking the lordotic curve of rods, the nuts were locked above all pedicle screws.

For the OPSF technique, the standard midline longitudinal posterior approach was applied from the upper to lower levels of the pedicle. Wiltse's approach was used to split between the longissimus and multifidus muscles. The screw was inserted using a normal technique and the screw was rechecked using fluoroscopy in AP 
and lateral views. The proper lengths of rods were bended and applied, then a nut was inserted.

The measurement technique was used to evaluate the magnitude of the kyphotic deformity, measuring the angle between the inferior endplate of the vertebrae above and the superior endplate of the vertebrae below the fracture vertebrae body.

The data were collected from patients' medical records such as blood loss, length of stay and postoperative pain days 1 and 3 using the visual analogue scale (VAS). The pre- and postoperative kyphotic angles were measured and calculated for kyphotic angle reduction. Data were presented in mean, standard deviation (SD), frequency, percentage and the independent t-test was used to test between the two approaches.

\section{Results}

From January 2017 to December 2019, demographic data of 54 thoracolumbar fractures operated at Rayong Hospital showed the mean of age was 32.35 years $(\mathrm{SD}=8.52)$, mostly male $(29,59.2 \%)$. In addition, configurations of spinal fractures were burst $(39,72.22 \%)$, and compression $(15,27.78 \%)$. In addition, the levels of the TL fractures were as followed: T11 level $(7,12.96 \%)$, T12 level (19, 35.18\%), L1 level (20, 37.04\%) and L2 level $(8,14.82 \%)$. Finally, causes of fractures included fall from height $(29,53.70 \%)$, traffic accident $(19,35.18 \%)$ and machine contusion (6, 11.12\%). Patient demographic data between the PPSF and OPSF groups did not significantly differ (Table 1).

Table1. Patient demographic data of the percutaneous pedicle screw fixation and open pedicle screw fixation groups $(\mathrm{N}=54)$

\begin{tabular}{lccc}
\hline \multicolumn{1}{c}{ data } & $\begin{array}{c}\text { PPSF } \\
(\mathbf{N}=\mathbf{2 3})\end{array}$ & $\begin{array}{c}\text { OPSF } \\
(\mathbf{N}=\mathbf{3 1})\end{array}$ & p-value* \\
\hline Age(year) & $31 \pm 9$ & $34 \pm 8.16$ & 0.56 \\
Gender & & & \\
$\quad$ male & $11(47.82 \%)$ & $23(74.19 \%)$ & 0.13 \\
female & $12(52.18 \%)$ & $8(25.81 \%)$ & \\
Characteristic of fracture & & & \\
Burst Fracture & $17(73.91 \%)$ & $22(70.96 \%)$ & 0.63 \\
Compression Fracture & $6(26.09 \%)$ & $9(29.04 \%)$ & \\
Level of fracture & & & \\
T11 & $1(4.35 \%)$ & $6(19.36 \%)$ & \\
T12 & $10(43.48 \%)$ & $9(29.03 \%)$ & \\
L1 & $9(39.13 \%)$ & $11(35.48 \%)$ & \\
L2 & $3(13.04 \%)$ & $5(16.13 \%)$ & \\
Causation of fracture & & & \\
Fall from height & $11(47.82)$ & $18(58.06)$ & \\
Traffic accident & $10(43.47)$ & $9(29.03)$ & \\
Machine contusion at back & $2(8.71)$ & $4(12.91)$ & \\
\hline
\end{tabular}

Percutaneous pedicle screw fixation (PPSF), Open pedicle screw fixation (OPSF) *Independent t-test 
Preoperative kyphotic angle of the PPSF and OPSF groups were $27.52 \pm 2.92$ degrees and $27.97 \pm 2.76$ degrees, respectively with no significant difference. Postoperative kyphotic angles of the PPSF and OPSF groups were $3.09 \pm 0.79$ and $3.10 \pm 0.79$ degrees, respectively, without significant difference (Table 2). The average kyphotic angle reduction of the PPSF and OPSF groups was equal at 24 degrees.

As shown in Table 3, using VAS, postoperative pain was evaluated at the first post-operative day of both groups. The VAS of the PPSF and OPSF groups were $6.43 \pm 0.94$ and $6.61 \pm 0.98$, respectively. Furthermore, the pain levels at day 3 of both techniques were $2.78 \pm 0.90$ and 2.94 \pm 0.85 , respectively. As a result, the average pain level of both groups between days 1 and 3 did not significantly differ. In addition, the length of stay of the PPSF and OPSF groups were 6.04 \pm 1.10 and $10.90 \pm 0.97$ days, respectively $(p=0.98)$. On the other hand, duration of post-operative day of both groups significantly differed at $3.09 \pm 0.59$ and $6.16 \pm 1.00$ days, respectively.
For intraoperative period, operative time of both groups were $68.3 \pm 7.32$ and $66.71 \pm 6.59 \mathrm{~min}$, respectively $(p=0.23)$. However, blood loss of both groups significantly differed at $44.35 \pm 15.02$ and $466.13 \pm 87.92 \mathrm{~mL}$, respectively.

\section{Complications}

Complications occurring among surgery cases included improper screw in the PPSF group (three cases) but none occurred in the OPSF group. However, this problem could be solved using fluoroscopy assisted without neurological deficit.

\section{Discussion}

Fixation of the thoracolumbar spinal fracture using OPSF has been used substantially and constitutes a standard method. However, a new procedure to fix comprises the PPSF a considerably popular technique to correct deformity of the spine including unstable thoracolumbar fracture. The advantage of this new method includes minimizing injury to the musculo-tendinous

Table2. Results of kyphotic angle comparing between the PPSF and OPSF groups

\begin{tabular}{|c|c|c|c|}
\hline data & $\begin{array}{c}\text { PPSF } \\
(\mathrm{N}=23) \\
\text { mean } \pm \text { SD }\end{array}$ & $\begin{array}{c}\text { OPSF } \\
(\mathrm{N}=31) \\
\text { mean } \pm \text { SD }\end{array}$ & $p$-value* \\
\hline Pre-operative kyphotic angle & $27.52(2.92)$ & $27.97(2.76)$ & 0.90 \\
\hline Post-operative kyphotic angle & $3.09(0.79)$ & $3.10(0.79)$ & 0.88 \\
\hline Kyphotic angle reduction & $24.43(2.74)$ & $24.87(2.55)$ & 0.79 \\
\hline
\end{tabular}

Percutaneous pedicle screw fixation (PPSF), Open pedicle screw fixation (OPSF) *Independent t-test

Table3. Results of outcome comparing between the PPSF and OPSF groups

\begin{tabular}{lccc}
\hline \multicolumn{1}{c}{ data } & $\begin{array}{c}\text { PPSF } \\
(\mathbf{N = 2 3 )}\end{array}$ & $\begin{array}{c}\text { OPSF } \\
(\mathbf{N}=\mathbf{3 1})\end{array}$ & $\boldsymbol{p}$-value* \\
\hline Postoperative pain at Day 1 & $6.43 \pm 0.94$ & $6.61 \pm 0.98$ & 0.56 \\
Postoperative pain at Day 3 & $2.78 \pm 0.90$ & $2.94 \pm 0.85$ & 0.94 \\
Length of stay (day) & $6.04 \pm 1.10$ & $10.90 \pm 0.97$ & 0.98 \\
Duration of post-operative day & $3.09 \pm 0.59$ & $6.16 \pm 1.003$ & 0.04 \\
Duration of surgery (min) & $68.3 \pm 7.32$ & $66.71 \pm 6.59$ & 0.23 \\
Blood loss during surgery (mL) & $44.35 \pm 15.02$ & $466.13 \pm 87.92$ & 0.01 \\
\hline
\end{tabular}

Percutaneous pedicle screw fixation (PPSF), Open pedicle screw fixation (OPSF) *Independent t-test 
unit, reducing blood loss, decreasing length of stay and lessen postoperative pain. ${ }^{(7-13)}$

This study compared the PPSF with OPSF techniques wherein reduced blood loss was significantly observed $(p<0.01)$. Moreover, the number of postoperative days decreased significantly $(p<0.05)$ as in other related studies. $(9,10,18,19)$ However, lengths of stay of both groups did not differ due to insufficient operative rooms. For this reason, pre-operative time differed for each person.

Regarding the measured kyphotic angle, the PPSF group was corrected 27.52 to 3.09 degrees while the OPSF group was corrected 27.97 to 3.10 degrees. Both were not divergent as in related studies. ${ }^{(9,10,18,22)}$ In addition, duration of surgery of both methods did not differ similar to those of Dong et al. and Grossbach et al. ${ }^{(20,24)}$ In contrast to other studies ${ }^{(9,18,25)}$, the PPSF revealed shorter operative time than that of the OPSF group; nonetheless, duration of surgery might have been related to experiences of surgeons as well as the use of applied instruments.

Pain levels reported at the first operativeand third operative day did not differ although a related study reported that the PPSF group had pain scores lower than those of the OPSF group. $(10,12,18,20)$

However, McAnany et al. ${ }^{(9)}$ showed similar results as this study. This study encountered some limitations, i.e., the small sample size could not clarify the difference of postoperative pain which could have occurred. In addition, the instrument used for percutaneous fixation could have increased surgery costs; however, benefits were obtained, i.e., reduce blood loss and lower duration of hospital stay.

\section{Conclusion}

The PPSF technique reduced blood loss and decreased length of hospital stay. Nevertheless, both techniques did not differ in terms of postoperative pain, kyphotic angle reduction and surgery duration.

\section{Acknowledgement}

The author would like to thank Dr. Piyapong Chinchum for his support and guidance.

\section{References}

1. Gertzbein SD. Scoliosis Research Society. Multicenter spine fracture study. Spine 1992; 17: 528-40.

2. Hasler RM, Exadaktylos AK. Bouamra O. Benneker LM, Clancy M, Sieber R, et al. Epidemiology and predictors of spinal injury in adult major trauma patients: European cohort study. Eur Spine J 2011; 20: 2174-80.

3. Denis F. The three column spine and its significance in the classification of acute thoracolumbar spinal injuries. Spine 1983; 8: 817-31

4. Vaccaro AR, Lehman RA Jr, Hurlbert RJ, Anderson PA, Harris M, Hedlund R, et al. A new classification of thoracolumbar injuries: the importance of injury morphology, the integrity of the posterior ligamentous complex, and neurologic status. Spine 2005; 30: 2325-33.

5. Vaccaro AR, Zeiller SC, Hulbert RJ, Anderson PA, Harrin M, Hedlund R, et al. The thoracolumbar injury severity score: a proposed treatment algorithm. J Spinal Disord Tech 2005; 18: 209-15.

6. Lenarz CJ, Place HM. Evaluation of a new spine classification system, does it accurately predict treatment? J Spinal Disord Tech 2010; 23: 192-6.

7. Cimatti M, Forcato S, Polli F, Miscusi M, Frati A, Raco A. Pure percutaneous pedicle screw fixation without arthrodesis of 32 thoracolumbar fractures: clinical and radiological outcome with 36-month follow-up. Eur Spine J 2013; 22 (Suppl 6): S925-32.

8. Kim DY, Lee SH, Chung SK, Lee HY. Comparison of multifidus muscle atrophy and trunk extensor muscle strength: percutaneous versus open pedicle screw fixation. Spine 2005; 30: 123-9.

9. McAnany SJ, Overley SC, Kim JS, Baird EO, Qureshi SA, Anderson PA. Open versus minimally invasive fixation techniques for thoracolumbar trauma: A meta-analysis. Global Spine J 2016; 6: 186-94.

10. Phan K, Rao PJ, Mobbs RJ. Percutaneous versus open pedicle screw fixation for treatment of thoracolumbar fractures: Systematic review and meta-analysis of comparative studies. Clin Neurol Neurosurg 2015; 135: 85-92. 
11. Vanek P, Bradac O, Konopkova R, de Lacy P, Lacman J, Benes V. Treatment of thoracolumbar trauma by short-segment percutaneous tranpedicular screw instrumentation: prospective comparative study with a minimum 2-year follow-up. J Neurosurg 2014; 20:150-6.

12. Wang H, Zhou Y, Li C, Liu J, Xiang L. Comparison of open versus percutaneous pedicle screw fixation using the sextant system in the treatment of traumatic thoracolumbar fractures. Clin Spine Surg 2017; 30: E239-e46.

13. Wild MH, Glees M, Plieschnegger C, Wenda K. Five-year follow-up examination after purely minimally invasive posterior stabilization of thoracolumbar fractures: a comparison of minimally invasive percutaneously and conventionally open treated patients. Arch Orthop Trauma Surg 2007; 127: 335-43.

14. Wiltse LL, Bateman JG, Hutchinson RH, Nelson WE. The paraspinal sacrospinalissplitting approach to the lumbar spine. J Bone Jt Surg 1968; 50: 919-26.

15. LeeJK, Jang JW,Kim TW, Kim SH, Moon SJ. Percutaneous short-segment pedicle screw placement without fusion in the treatment of thoracolumbar burst fractures: is it effective?: comparative study with open short-segment pedicle screw fixation with posterolateral fusion. Acta Neurochir 2013; 155: 2305-12.

16. Fitschen-Oestern s, Scheuerlein F, Weuster M, Klueter T, Menzdorf L, Varoga D. et al. Reduction and retention of thoracolumbar fractures by minimally invasive stabilization versus open posterior instrumentation. Injury 2015; 46 (Suppl 4): S63-70.

17. Dong SH, Chen HN, Tian JW, Xia T, Wang $\mathrm{L}$, Zhao QH, et al. Effects of minimally invasive percutaneous and trans-spatium intermuscular short-segment pedicle instrumentation on thoracolumbar mono-segmental vertebral fractures without neurological compromise, Orthop Traumatol Surg Res 2013; 99: 405-11.

18. Grossbach AJ, Dahdaleh NS, Abel TJ, Woods GD, Dlouhy BJ, Hitchon PW. Injuries of the thoracolumbar spine: open fusion versus percutaneous pedicle screw fixation. J Neurosurg 2013; 35: E2.

19. Rahul PP, Joshi V, Pemecha C, Kumar P, Bisnoi UP, Singh O. Comparative study between short segment open versus percutaneous pedicle screw fixation with indirect decompression in management of acute burst fracture of thoracolumbar spine with minimal neurological deficit in adults. J Spine 2016; 05: 1-5. 